\title{
Representatividade de gênero em emojis: uma pesquisa exploratória comparativa entre São Paulo e Recife sobre a congruência de estratégias de uso e produção pictográfica em plataformas digitais Gender representation in emojis: an exploratory research of the congruence between use and pictographic production in digital platforms
}

\author{
Raquel Klafke, Hana Leite, Daniela Hanns \& Hans Waechter
}

emoji, design, gênero, uso

\begin{abstract}
Nos últimos anos, o Unicode Consortium se dedicou a ampliar a representatividade de gênero em emojis, pictogramas digitais que potencializam a comunicação textual. Contudo, apesar de seus esforços, ferramentas indicam que os mesmos signos são muito pouco utilizados. Para investigar a questão, apresenta-se neste artigo o resultado de estudo exploratório sobre critérios empregados no uso de emojis por seus usuários, que considerou um panorama comparativo entre usuários das cidades Recife e São Paulo com métodos quanti e qualitativos, enfoque sobre o marcador "gênero". A pesquisa quantitativa contou com 85 respondentes e foi baseada nas dimensões sintática, semântica e pragmática da imagem. A etapa qualitativa foi conduzida com 13 entrevistas presenciais para aprofundamento. Como resultado, observou-se alguns critérios recorrentes, como (1) a representação de identidade por mais de um aspecto além de gênero (semântico), (2) a similaridade física como aspecto relevante (sintático) e (3) escolhas a partir de usos específicos, como expressão de emoções (pragmática). Concluiu-se, a partir de depoimentos, dados e padrões, que a dimensão que mais afeta a questão investigada é a pragmática: mesmo projetados para representar diversos gêneros, os emojis analisados carecem de características que os tornem "expressivos" - como expressões faciais diferentes -, fazendo com que, na prática, não sejam utilizados. O estudo aponta, portanto, que compreender de forma mais ampla a dimensão de uso de signos digitais, abrangendo seus significados e aplicações por parte de usuários, contribui para a produção de signos mais assertivos para uso em mensageiros instantâneos.
\end{abstract}

\section{Emoji, design, gender, use}

For the past years, the Unicode Consortium has broadened gender representation in emoji, digital pictograms that improve written communication. However, despite the efforts, tools show that those signs are not very used. To understand this issue, this paper presents the results of an exploratory research on users criteria to choose and use emoji, considering users in the cities Recife and São Paulo with quantitative and qualitative methods focusing on gender. The quantitative approach was based on syntatic, semantic and pragmatic questions, held among 85 users. The qualitative approach was held among 13 users with deeper interviews. As result, some recurring patterns were observed, such as (1) the selfrepresentation by several aspects besides gender (semantic); (2) the physical similarity as a relevant issue (syntatic); and (3) choices based on specific uses, as emotional expression (pragmatic). It's concluded, based on testimonies, data and patterns, that the pragmatic dimension is the most significative regarding the low usage of representative emoji, due to their lack of diverse facial expressions. This research shows, therefore, that a deeper comprehension about the pragmatic dimension of emoji can help the design of more meaningful emoji, improving the experience of digital communication.

\section{Introdução}

O presente artigo resulta da investigação de critérios de escolha de emojis empregados por usuários tendo como foco o marcador "gênero". De acordo com o Unicode Consortium (Davis \& Edberg, 2017), emojis são

pictogramas (símbolos pictóricos) comumente apresentados com aparência cartunesca e usados em conjunto com textos. Eles representam coisas como faces, clima, veículos e prédios, comidas e

\author{
Anais do 9 CIDI e 9 CONGIC \\ Luciane Maria Fadel, Carla Spinillo, Anderson Horta, \\ Cristina Portugal (orgs.) \\ Sociedade Brasileira de Design da Informação - SBDI \\ Belo Horizonte | Brasil | 2019 \\ ISBN 978-85-212-1728-2
}

Proceedings of the 9th CIDI and 9th CONGIC

Luciane Maria Fadel, Carla Spinillo, Anderson Horta, Cristina Portugal (orgs.)

Sociedade Brasileira de Design da Informação - SBDI

Belo Horizonte | Brazil | 2019

ISBN 978-85-212-1728-2 
bebidas, animais e plantas, ou ícones que representam emoções, sentimentos ou atividades. (tradução nossa)

Dentre vários aspectos que compõem uma percepção de identidade, escolheu-se focar "gênero" em função do histórico recente de projetos concebidos para promover maior representatividade de mulheres. De acordo com dados apresentados por Been et al. (2016), mulheres compõem a maior parcela de usuários de emoji. Abordar a questão é, portanto, de interesse do design enquanto projeto em ação - de aprimorar experiência e de se pensar politicamente a linguagem (Kress \& van Leeuwen, 2006).

Contudo, de acordo com as ferramentas EmojiTracker (2013) (Figura 1) e EmojiStats (2019) (Figura 2), que contabilizam o uso de emojis nas plataformas Twitter e iOS, emojis "representativos" são pouco usados em comparação com outros emojis (Figura 3). Em Leite (2018), confirma-se a predominância no padrão de uso de emojis que representem expressões, emoções e gestos (como smileys $(-)$ ). Nota-se, portanto, que existe um descompasso entre a implementação de emojis pelo Unicode e o uso efetivo desses emojis por usuários.

Figura 1: Interface do contador Emojitracker (elaborado pelos autores a partir de captura de tela).

emojitracker: realtime emoji use on twitter

\begin{tabular}{|c|c|c|c|c|c|c|c|c|c|}
\hline 8 & 2486717949 & $\vartheta$ & 1195452888 & 7 & 964461468 & (3) & 905497580 & (86) & 735726000 \\
\hline$\bullet$ & 721024076 & (:) & 601860746 & (3) & 488590055 & 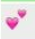 & 472151257 & (3) & 455300933 \\
\hline (하) & 410916279 & (2) & 377254384 & (2) & 352088992 & 8 & 349275837 & (:) & 341802539 \\
\hline (궁 & 323930113 & (3) & 288695281 & bا & 251080047 & 당 & 234240757 & 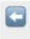 & 228350922 \\
\hline ds & 227180299 & $\therefore$ & 223994810 & (우) & 223940958 & (20) & 223082986 & $\theta$ & 219280169 \\
\hline 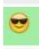 & 216648799 & s & 209594987 & $\bullet$ & 198279736 & $\theta$ & 194743184 & 象 & 186719063 \\
\hline ;궁 & 185627204 & tit & 185442950 & 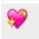 & 175363838 & 2 & 173564014 & $\theta$ & 171674711 \\
\hline w & 171594032 & 8 & 163368041 & (:) & 157882721 & (6) & 157537671 & ; & 156605042 \\
\hline ()ㅜ & 146668069 & (9) & 143271539 & (:) & 139653945 & (2) & 139206660 & (2) & 138470400 \\
\hline$\nabla$ & 132275839 & "E & 130056099 & (:) & 128386378 & $\sigma$ & 126558656 & 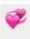 & 120271752 \\
\hline
\end{tabular}

Figura 2: Interface do contador EmojiStats (elaborado pelos autores a partir de captura de tela).

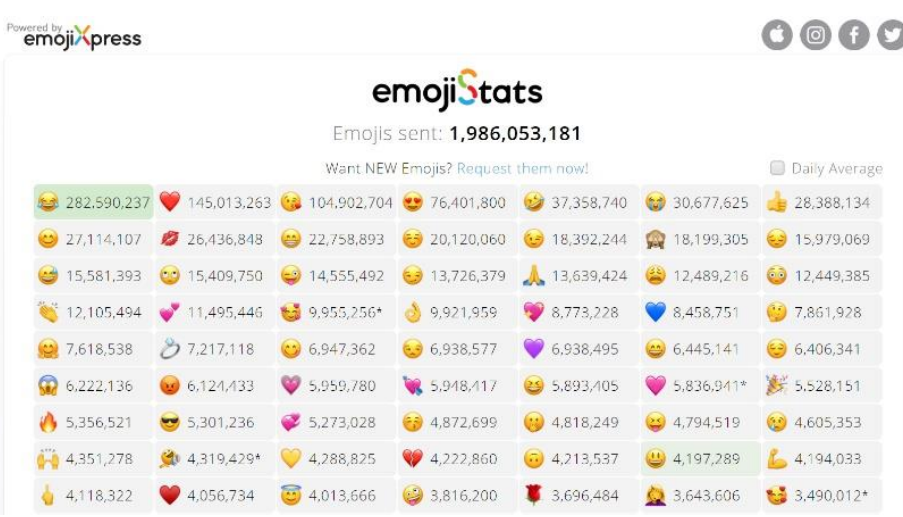


Figura 3: Exemplos de emojis "representativos" e "smiley" (elaborado pelos autores com imagens disponibilizadas no portal Emojipedia).

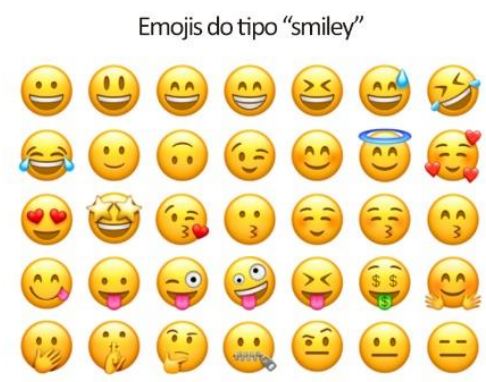

Emojis de pessoas ("representativos")

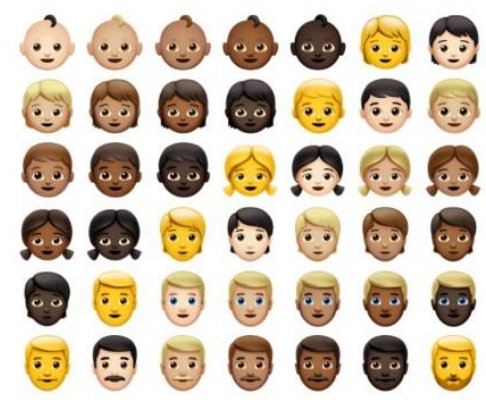

Neste estudo, parte-se da verificação exploratória de critérios de uso de emojis. O artigo está dividido em: Método, que traz as abordagens quantitativa e qualitativa do estudo; Objeto de Estudo e sua contextualização; e Resultados, com o fito de "otimizar questões de estrutura, significado e uso pelo sujeito em contexto determinado, visando a interação com a informação de modo acessível, compreensível, utilizável e simples" (Passos, Mealha \& Lima-Marques, 2015, p. 1015).

O trabalho deriva de estudos anteriores de Leite (2018) e Klafke (2019), que investigam as relações entre produção e uso de emojis nas cidades de Recife e São Paulo, respectivamente, oferecendo um parâmetro comparativo geográfico para análise.

\section{Objeto de estudo}

\section{Emoji, smiley, emoticon}

O meio escrito na comunicação digital, de natureza verbal, carece de elementos típicos de interações sociais - como expressões faciais, gestos e sons -, precisando de complementos para aperfeiçoar sua aplicação pragmática (Gulşen, 2016). Os emoticons foram uma primeira tentativa: mapeados desde os anos 80 , são representações tipográficas que conferem à palavra uma nova visualização gráfica, como ":-)" (felicidade) ou ":-(" (tristeza).

Os emoticons são inspirados nas expressões humanas, como o smiley - ícone amarelo com um sorriso, utilizado como referência para signos digitais nos anos 90 e início dos anos 2000. À combinação tipográfica se confere volume, forma e cor, ampliando as possibilidades de comunicação. A relação evolutiva entre smiley e emoticon se torna evidente ao observar-se que essas palavras eram usadas como sinônimos (Klafke, 2019).

Tecnicamente, emojis são gráficos codificados como fonte tipográfica. É uma forma de representação pictórica que amplia as possibilidades abertas por emoticons e smileys. Os emojis podem ser apresentados como: 1) emojis - gráficos, com design policromático; 2) texto - emojis textuais (glifos), semelhantes aos dingbats, com design monocromático mas com interface de entrada diferente da alfanumérica (Figura 4) (Leite, 2018). 
Figura 4: Gráfico da relação entre representação gráfica, interface de entrada e complexidade de codificação dos emojis e fontes tipográficas (Leite, 2018, p. 23).

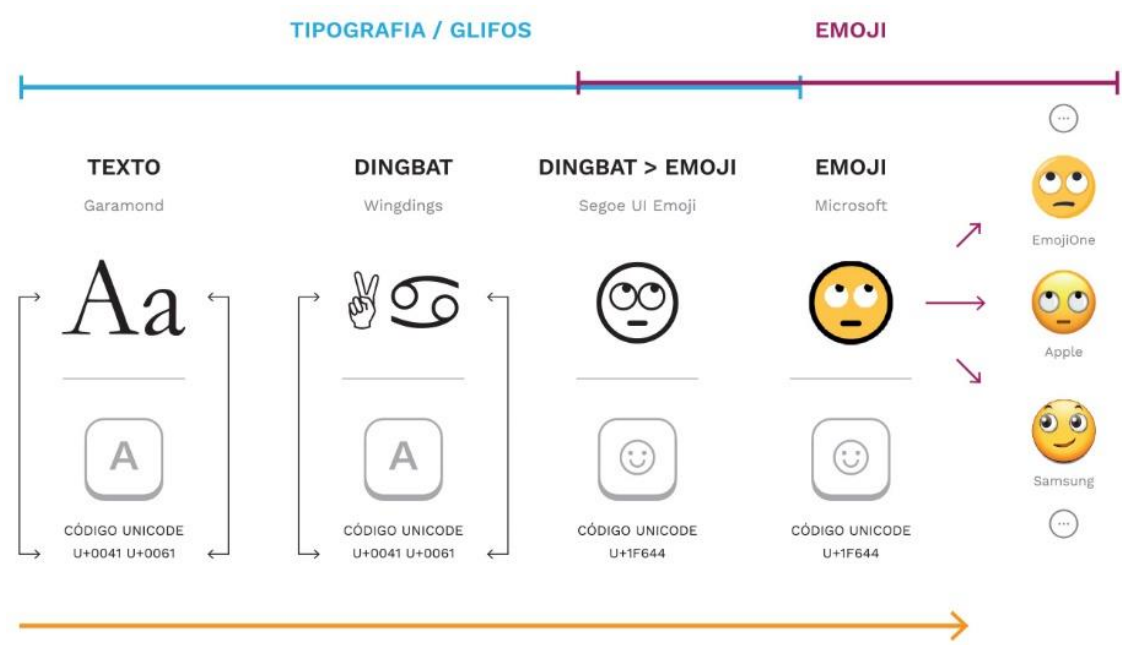

COMPLEXIDADE DE CODIFICAÇÃO (ACESSIBILIDADE DE ENTRADA DOS CARACTERES)

$\rightarrow$ INTERFACE DE ENTRADA ALFANUMÉRICA (FISICA OU DIGITAL)

$\rightarrow$ INTERFACE DE ENTRADA DIGITAL PARA EMOJIS

\section{O Consórcio Unicode e a produção de signos}

O Unicode Consortium é uma organização internacional sem fins lucrativos que se dedica a desenvolver padrões de codificação e decodificação universais de caracteres digitais para proporcionar comunicação consistente entre diferentes plataformas. A partir dos anos 2000, desenvolveu uma forma particular de apresentação de caractere: o emoji.

A produção de emojis segue um percurso anual de ideação, aprovação e desenvolvimento (Klafke, 2019): abre-se um processo livre de submissão de propostas, analisadas por um subcomitê dedicado ao assunto (Unicode Emoji Sub-Committee, com membros como Apple, Microsoft, Facebook e Google). Uma vez aprovadas, podem ser implementadas pelas principais empresas do mercado (Figura 5).

Figura 5: Exemplo de emojis pertencentes à mesma categoria (Unicode, 2019).

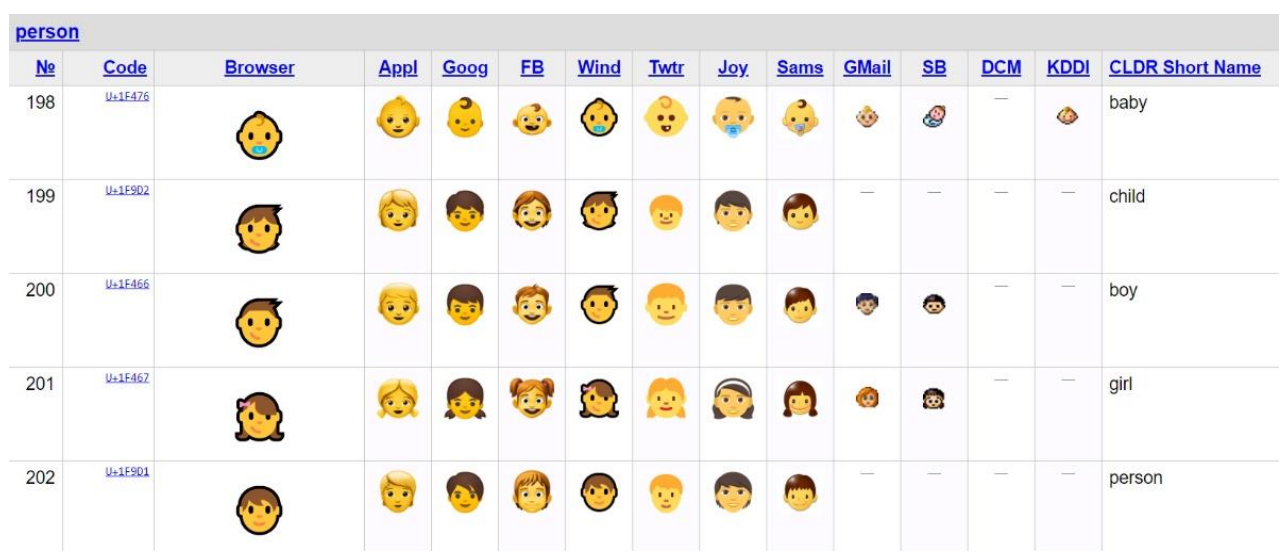

O processo de criação e implementação de emojis levanta questões sobre produção de signos, pois muitas propostas aprovadas são apresentadas pelas mesmas empresas que participam do Unicode (Klafke, 2019). A pauta de gênero foi um interesse específico: com o projeto Expanding Emoji Professions: Reducing Gender Inequality, (Been et al., 2016) o

Anais do 9 Congresso Internacional de Design da Informação | CIDI 2019

Proceedings of the 9th Information Design International Conference

Anais do $9^{\circ}$ Congresso Nacional de Iniciação Científica em Design da Informação | CONGIC 2019

Proceedings of the $9^{\text {th }}$ Information Design Student Conference 
número de discussões sobre representatividade de mulheres na comunicação digital aumentou. Desde então, cada atualização do padrão Unicode considera uma expansão de signos em relação ao tema gênero, buscando tornar a comunicação digital mais representativa (Figura 6).

Figura 6: Exemplo da expansão de emojis relacionados a gênero ao longo de 2015 a 2019 (Klafke, 2019).

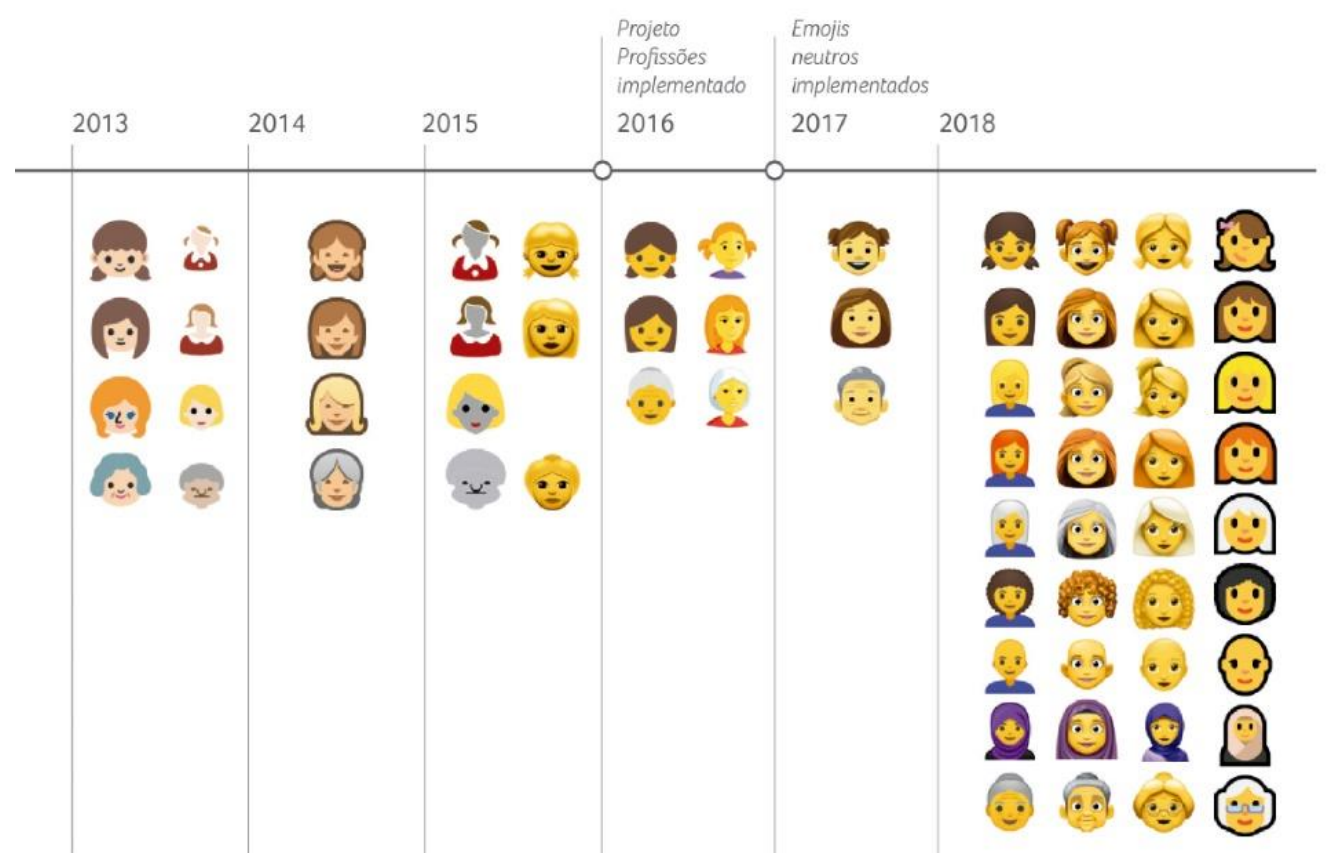

\section{Uma perspectiva de gênero}

Aqui, admite-se a perspectiva de Butler (2016) para se compreender gênero. A autora desenvolve o conceito de performatividade, ou sua construção a partir de atos repetidos que naturalizam discursos e noções relacionados a reprodução, sexualidade e identidade. Esse modelo permite visualizar interpretações mais representativas e igualitárias, uma vez que é possível modificar padrões e subverter noções naturalizadas de gênero - ao que chama de atos emancipatórios.

O modelo de Butler (2016) oferece bases com aplicações práticas no campo do design, pois cultura material e imaterial podem ser interpretadas como atos performativos. O design é capaz, portanto, de naturalizar ou subverter noções de gênero (Klafke, 2019). Ao utilizar emojis como recurso para fortalecer um determinado posicionamento em relação ao gênero, o Unicode Consortium produz discursos com a intenção ideológica de igualdade e representatividade, tornando-se um exemplo de ato emancipatório.

Se o design de informação busca atender às necessidades humanas a partir da articulação de objetos dotados de funções simbólicas, estéticas e práticas (Braida \& Nojima, 2014, p. 21), os emojis possuem um alto potencial para se explorar a questão de gênero: de uma perspectiva estética, por tangibilizar visualmente a diversidade de representações; em termos práticos, por ampliar o vocabulário do dia-a-dia com novas possibilidades de autoidentificação; por último, em termos simbólicos, por dar visibilidade à discussão de representatividade feminina e sugerir uma quebra arbitrária de padrões comunicativos.

\section{Método}

Essa pesquisa foi elaborada a partir da combinação de métodos quantitativos e qualitativos de levantamento de dados. O objetivo da estratégia foi identificar padrões comuns de uso

Anais do 9o Congresso Internacional de Design da Informação | CIDI 2019 
relacionados às dimensões semântica, pragmática e sintática (Gomes Filho, 2006; Braida \& Nojima, 2014), enquanto a abordagem qualitativa auxiliou na compreensão acerca do juízo de usuários para uso de emojis específicos. Para compreensão de gênero, utilizou-se o modelo proposto por Butler (2016).

\section{Levantamento quantitativo: aplicação de questionário}

A etapa quantitativa foi realizada a partir de questionário desenvolvido e implementado pela ferramenta Typeform. As questões foram elaboradas a partir das dimensões semântica, pragmática e sintática, e o questionário foi disponibilizado on-line para residentes das cidades de Recife (28 respondentes) e São Paulo (57 respondentes). As imagens de emojis utilizadas para elaboração de perguntas são de autoria da empresa Apple, devido à popularidade que apresentam nos meios on-line e off-line (Figura 7).

Figura 7. Objetos produzidos a partir da estética de emojis da Apple (elaborado pelos autores a partir de registros fotográficos feitos em São Paulo ao longo de 2018).

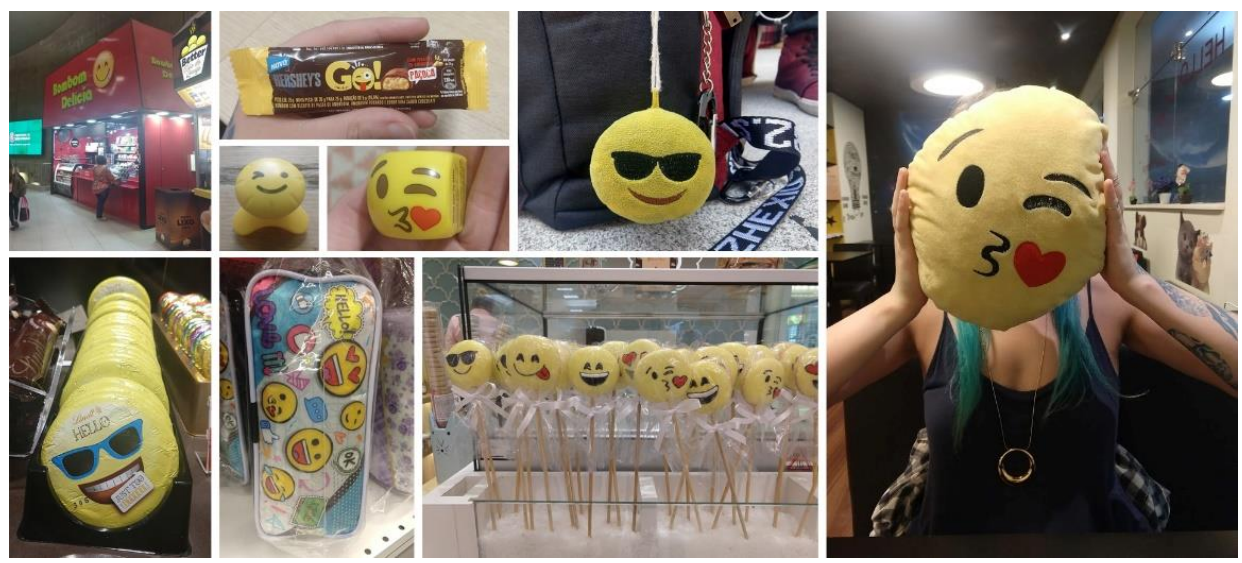

Em São Paulo, o acesso ao formulário foi distribuído em comunidade de pessoas relacionadas a tecnologia e empreendedorismo. Em Recife, o acesso ao formulário foi distribuído em comunidade de pessoas de profissões variadas das áreas de ciências humanas, da saúde e exatas, como design, engenharias, artes, economia, direito, e ciência da computação. Em ambas as cidades, os usuários possuíam alta afinidade com tecnologias, eram integrantes de classe média, possuíam educação superior incompleta ou completa e eram predominantemente brancos e pardos.

\section{Levantamento qualitativo: entrevistas}

As entrevistas foram realizadas com 13 respondentes (6 em Recife, 7 em São Paulo). O roteiro foi elaborado a partir de perguntas do questionário quantitativo. Manteve-se a opção de perguntas abertas para explorar os critérios de uso de seus usuários. O cruzamento de dados quantitativos e qualitativos permitiu a identificação de critérios empregados por usuários de emojis.

\section{Elaboração das perguntas}

As perguntas elaboradas para o questionário e entrevistas (Tabela 1) foram baseadas nas dimensões apresentadas por Gomes Filho (2006): sintática, semântica, pragmática. Por sintática, entende-se "o conjunto de relações que existe entre as unidades: palavras, signos e símbolos que formam o vocabulário" (como se estruturam visualmente, ver Figuras 8 a 12); por semântica "a dimensão do próprio objeto e da coisa significada" (o que representam); e, por pragmática, "a relação entre os signos e seus usuários, ou seja, seus intérpretes" (frequência, uso e finalidade). 


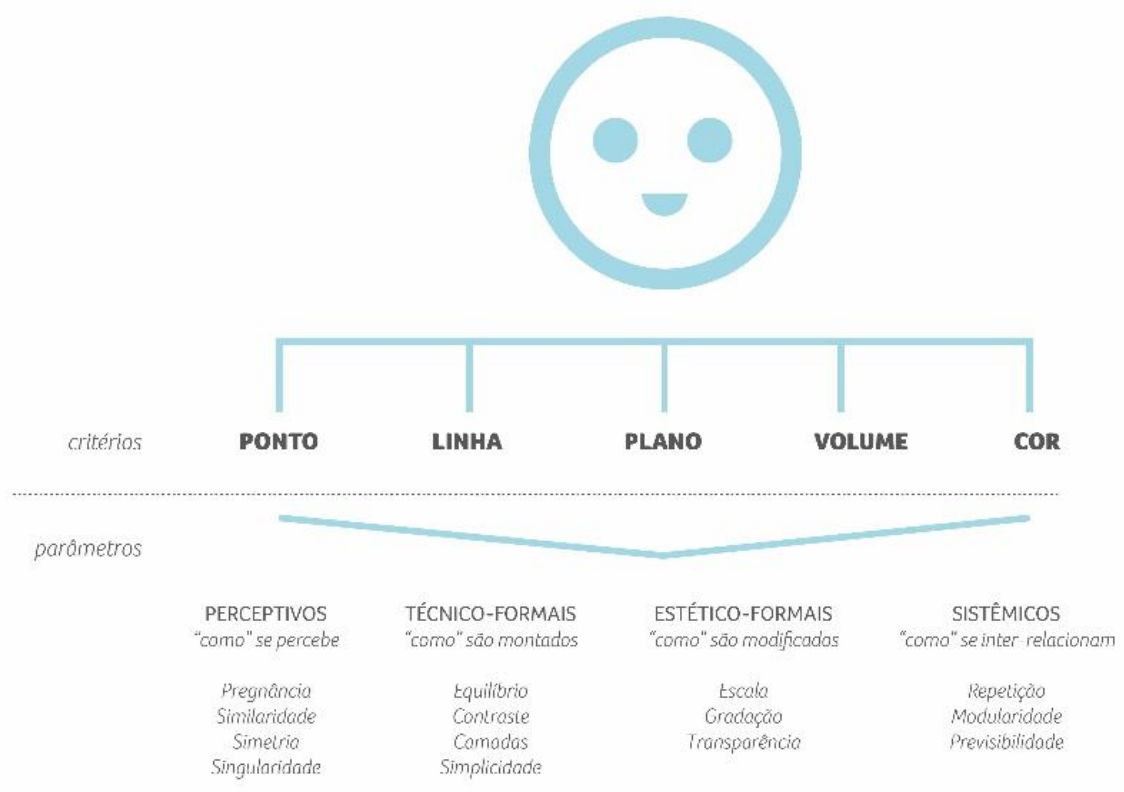

parâmetros PERCEPTIVOS
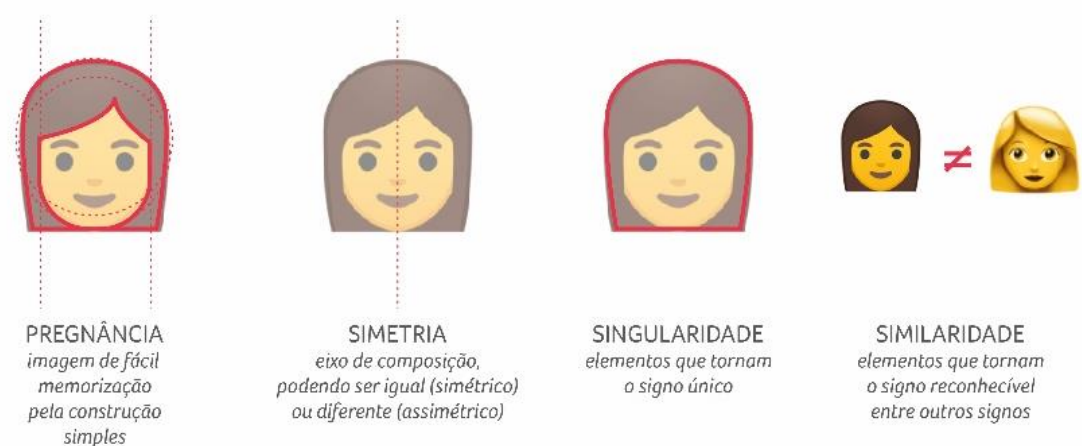

parâmetros TÉCNICO-FORMAIS

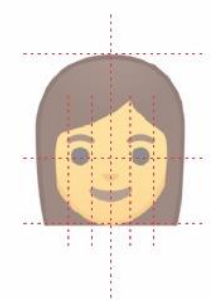

EQUILÍBRIO disposição dos elementos de forma estática ou dinâmica

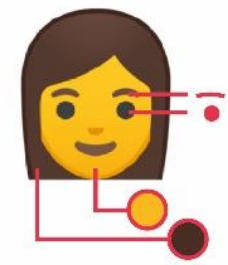

CONTRASTE variação entre extremos de determinada categoria

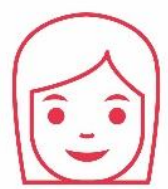

SIMPLICIDADE nivel de detalhamento

ou quantidade de elementos na imagem

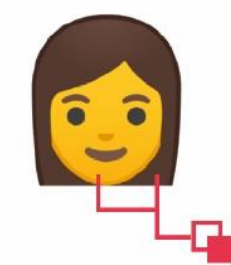

CAMADAS disposiçāo de elementos em niveis diferentes de profundidade 

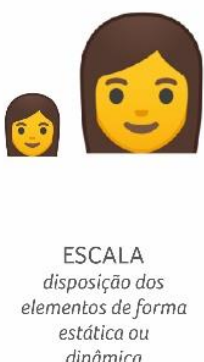

parâmetros SISTÊMICOS
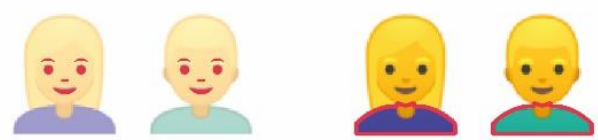

MODULARIDADE

unidades replicáveis

em um mesmo sistema

\footnotetext{
REPETIÇÃO

caracteristicas que

de um mesmo sistema
}

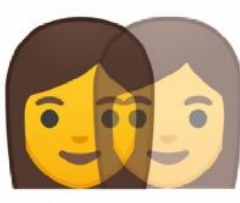

TRANSPARENNCIA

opacidade da imagem e seus elementos

Tabela 1: Relação de perguntas relacionadas às dimensões pragmáticas, sintáticas e semânticas (elaborado pelos autores).

\begin{tabular}{ll|l|l} 
Abordagem & Pergunta & Dimensão \\
\hline Quantitativa & $\begin{array}{l}\text { Com que frequência } \\
\text { você utiliza emojis em } \\
\text { mensagens (balões } \\
\text { de conversa)? }\end{array}$ & $\begin{array}{l}\text { Entender a presença de emojis no } \\
\text { processo de comunicação dos } \\
\text { usuários. }\end{array}$ & Pragmática \\
\cline { 2 - 3 } $\begin{array}{l}\text { Com qual finalidade } \\
\text { você usa emojis? }\end{array}$ & $\begin{array}{l}\text { Entender por que usuários optam } \\
\text { por usar emojis dentre suas } \\
\text { ferramentas de comunicação. }\end{array}$ & Pragmática \\
& $\begin{array}{l}\text { Na sua opinião } \\
\text { [escala], o quanto } \\
\text { emojis representam } \\
\text { você? }\end{array}$ & $\begin{array}{l}\text { Explorar a assertividade do emoji } \\
\text { enquanto solução gráfica para se } \\
\text { representar. }\end{array}$ & Semântica \\
$\begin{array}{l}\text { Qual dos grupos } \\
\text { abaixo apresenta } \\
\text { emojis que, na sua } \\
\text { percepção, mais } \\
\text { representam você? }\end{array}$ & $\begin{array}{l}\text { Entender que significados usuários } \\
\text { atribuem a emojis para considerá- } \\
\text { los representativos. }\end{array}$ & Semântica \\
$\begin{array}{l}\text { Do grupo } \\
\text { selecionado, com } \\
\text { qual emoji você mais } \\
\text { se identifica? }\end{array}$ & & \\
$\begin{array}{l}\text { Por que você } \\
\text { escolheu (ou não) as }\end{array}$ & Explorar os aspectos visuais que \\
tangibilizam o conceito de & Sintática e Semântica \\
\hline
\end{tabular}

Anais do 9o Congresso Internacional de Design da Informação | CIDI 2019

Proceedings of the 9th Information Design International Conference

Anais do $9^{\circ}$ Congresso Nacional de Iniciação Científica em Design da Informação | CONGIC 2019

Proceedings of the $9^{\text {th }}$ Information Design Student Conference 


\begin{tabular}{|c|c|c|c|}
\hline & $\begin{array}{l}\text { imagens anteriores } \\
\text { como emojis que } \\
\text { melhor representam } \\
\text { você? }\end{array}$ & $\begin{array}{l}\text { representação. } \\
\text { Entender que significados usuários } \\
\text { atribuem a emojis para considerá- } \\
\text { los representativos. }\end{array}$ & \\
\hline & $\begin{array}{l}\text { Considerando que } \\
\text { eles representem } \\
\text { você, por que os } \\
\text { emojis aqui } \\
\text { identificados não se } \\
\text { encontram entre os } \\
\text { mais utilizados em } \\
\text { seu dia a dia? }\end{array}$ & $\begin{array}{l}\text { Entender por que certos emojis não } \\
\text { são utilizados, mesmo identificados } \\
\text { como "representativos". } \\
\text { Explorar quais aspectos visuais } \\
\text { tornam os emojis "utilizáveis". }\end{array}$ & $\begin{array}{l}\text { Pragmática, Sintática e } \\
\text { Semântica }\end{array}$ \\
\hline \multirow[t]{5}{*}{ Qualitativa } & $\begin{array}{l}\text { Qual é a frequência } \\
\text { de uso de emojis? } \\
\text { Quais são os usos } \\
\text { mais comuns? Por } \\
\text { quê? }\end{array}$ & $\begin{array}{l}\text { Entender a presença de emojis no } \\
\text { processo de comunicação dos } \\
\text { usuários. }\end{array}$ & Pragmática \\
\hline & $\begin{array}{l}\text { Você costuma usar } \\
\text { esse emoji? Por quê? }\end{array}$ & $\begin{array}{l}\text { Entender por que certos emojis são } \\
\text { ou não utilizados, mesmo } \\
\text { identificados como } \\
\text { "representativos". }\end{array}$ & Pragmática \\
\hline & $\begin{array}{l}\text { O que, para você, } \\
\text { significa que os } \\
\text { "emojis representam } \\
\text { você"? }\end{array}$ & $\begin{array}{l}\text { Entender de forma ampla o } \\
\text { significado de "representação". }\end{array}$ & Semântica \\
\hline & $\begin{array}{l}\text { Qual dos emojis mais } \\
\text { representa você? Por } \\
\text { quê? }\end{array}$ & $\begin{array}{l}\text { Entender que significados usuários } \\
\text { atribuem a emojis para considerá- } \\
\text { los representativos. } \\
\text { Explorar os aspectos visuais que } \\
\text { tangibilizam o conceito de } \\
\text { representação. }\end{array}$ & Sintática e Semântica \\
\hline & $\begin{array}{l}\text { Na sua opinião, } \\
\text { emojis precisam ser } \\
\text { representativos? } \\
\text { Como podem ser } \\
\text { mais representativos? }\end{array}$ & $\begin{array}{l}\text { Explorar as possibilidades de } \\
\text { expansão de significados para } \\
\text { ampliar a dimensão de uso de } \\
\text { emojis. } \\
\text { Explorar os aspectos visuais que } \\
\text { tangibilizam o conceito de } \\
\text { representação. }\end{array}$ & Sintática e Semântica \\
\hline
\end{tabular}

Há de se destacar que, apesar da separação entre elas para fins didáticos, elas se interrelacionam, sobrepõem ou mesmo se anulam. Por isso uma pergunta pode explorar mais de uma dimensão.

\section{Resultados}

\section{Resultados quantitativos}

\section{Contexto Recife}

A cidade de Recife contou com 28 respondentes, sendo $54,39 \%$ com gênero declarado feminino e $45,61 \%$ com gênero declarado masculino. A faixa etária é bem distribuída na amostra, consistindo em $35,71 \%$ entre 26 a 30 anos, $28,57 \%$ entre 31 a 35 anos e $28,57 \%$ acima de 36 anos. 
A maioria das mulheres declara usar muitos emojis em quase todas as mensagens $(49,04 \%)$, enquanto homens respondem por $31,58 \%$ dos usuários que usam apenas em algumas mensagens. Homens tendem a usar emojis para economizar tempo ou substituir palavras, enquanto mulheres recorrem a critérios pessoais de comunicação, como fazer trocadilhos ou enfeitar textos. Contudo $96,43 \%$ do total considera-os para expressar emoções, seguido por $60,71 \%$ que utilizam para reforçar mensagens textuais (Figuras 13 e 14).

Figuras 13 e 14: Gráficos ilustrativos sobre hábitos de uso de usuários de emojis em Recife (elaborados pelos autores).

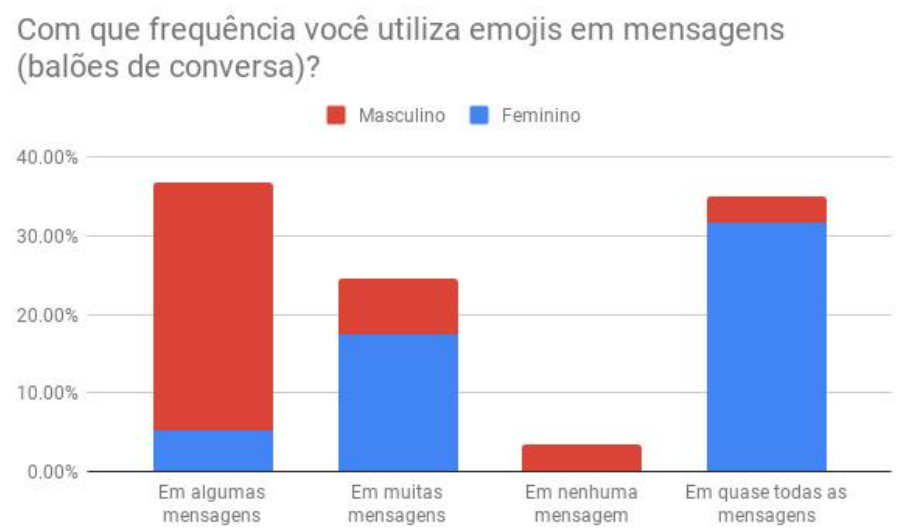

Qual é o uso mais comum para emojis?

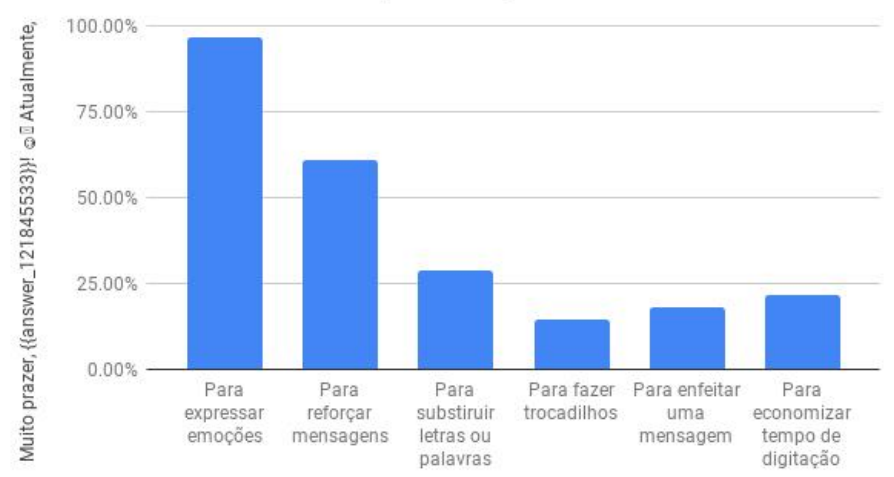

A maioria dos usuários $(67,86 \%)$ não considera que emoji os representa. As únicas usuárias que se sentem representadas $(14,29 \%)$ declaram utilizar os emojis apontados na pesquisa com frequência, sendo o principal argumento a semelhança com aparência física (função sintática). Os usuários que não os utilizam têm justificativas variadas, como "não costumo expressar meu visual por emojis" ou "porque uso mais os que possuem carinhas expressivas". As afirmações são coerentes com o resultado de uso mais comum de emojis, que coloca em primeiro plano a expressão de emoções como critério principal para a função pragmática (Rothenberg, 2013; Leite, 2018; EmojiXpress, 2019).

Em Recife, os respondentes selecionaram mais tons de pele diferentes do padrão amarelo, sugerindo maior abertura para expressão de etnias. Os grupos mais escolhidos estão representados na Figura 15. Também não citaram etnia em nenhuma justificativa possível entre as respostas abertas. Gênero não se destacou como um critério declaradamente relevante de representação, apesar dos participantes escolherem emojis do mesmo gênero que suas declarações.

Figura 15: Grupos mais escolhidos em pesquisa aplicada em Recife (elaborado pelos autores com imagens disponibilizadas em Emojipedia). 


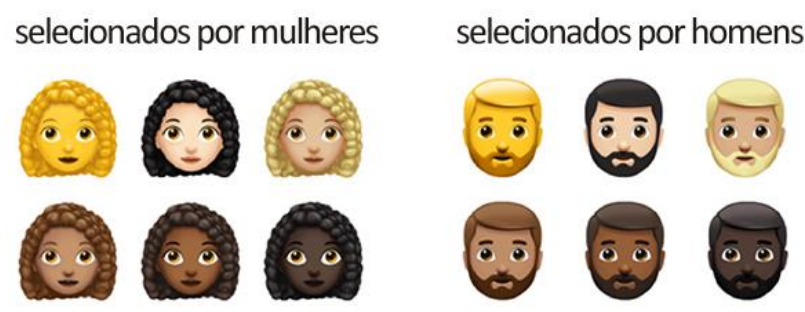

\section{Contexto São Paulo}

A cidade de São Paulo teve 57 respondentes: 54,39\% com gênero declarado feminino e $45,61 \%$ com gênero declarado masculino. A distribuição etária foi equilibrada: $35,09 \%$ com idades entre 19 a 25 anos, $33,33 \%$ entre 26 a 30 anos, $21,05 \%$ entre 31 a 35 anos e os demais acima de 36 anos.

Assim como em Recife, mulheres tendem a usar mais emojis, declarando usá-los na maioria de seus envios, e ambos os gêneros têm como função prática primária a expressão de emoções. "Enfeitar mensagens" foi mais recorrente em mulheres (Figuras 16 e 17). Emojis também são considerados para reforçar conteúdos textuais, correspondendo à utilidade prática declarada de $68,42 \%$ dos respondentes.

Figuras 16 e 17: Gráficos ilustrativos sobre hábitos de uso de usuários de emojis (elaborados pelos autores).

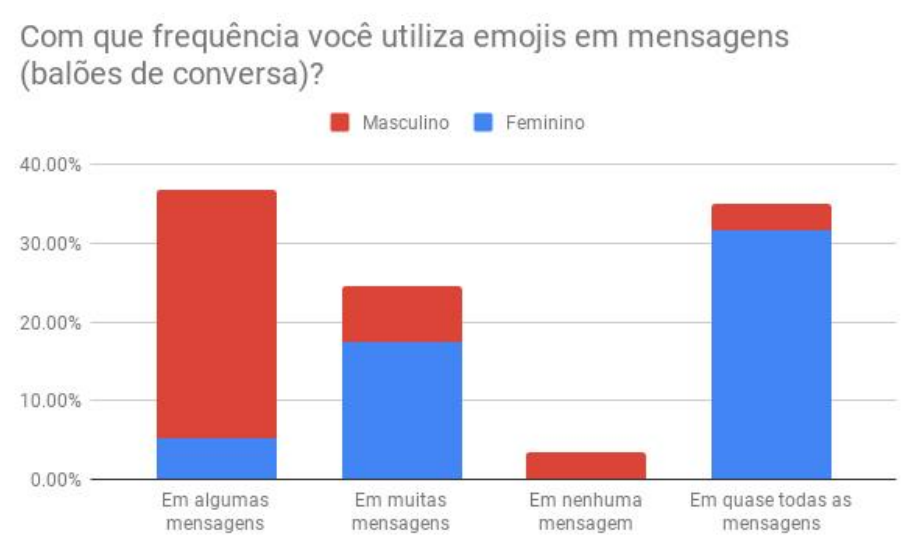

\section{Qual é o uso mais comum para emojis?}

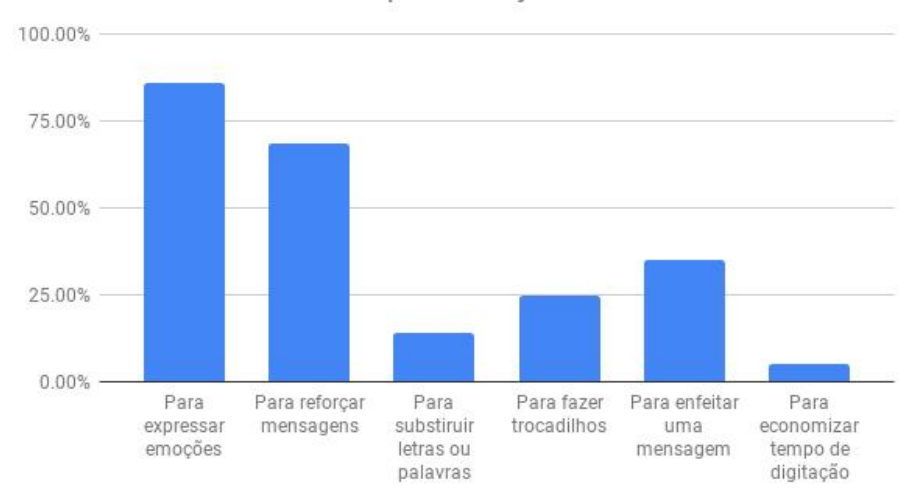

Diferente de Recife, mais da metade dos respondentes consideram que emojis os representam bem $(57,90 \%)$. Mulheres tendem a se sentir mais representadas. Os grupos mais citados como representativos correspondem aos apresentados na Figura 18. Houve bastante variação em relação a cores, refletindo uma variedade de representação dos participantes. A 
justificativa mais comum foi o critério aparência, como cor do cabelo, cor da pele ou mesmo penteado.

Figura 18. Grupos mais escolhidos em pesquisa aplicada em São Paulo (elaborado pelos autores com imagens disponibilizadas em Emojipedia).

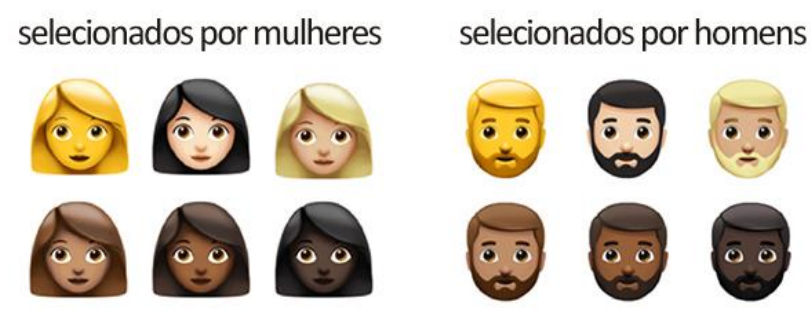

Apesar dos números, a maioria dos respondentes indicou que não utiliza os emojis apontados como representativos de si $(80,70 \%)$. Como justificativa, encontram-se os principais argumentos a falta de expressividade nas faces e a falta de aplicação prática em conversas cotidianas. Observa-se, portanto, um descompasso entre como usuários utilizam seus emojis e como eles são projetados para ampliar a representatividade em plataformas digitais.

O critério "gênero" não apareceu nas questões abertas em relação ao uso de emojis, apesar de haver uma correspondência direta entre gênero declarado e emoji escolhido como referencial de identificação. Etnia apresentou ocorrências explícitas, como "[...] a cor amarela deixa de lado a questão de raça".

Outro dado interessante se refere à usabilidade de emojis com diferentes tons de pele. Afirmações como "[...] escolher a amarela porque tenho preguiça de ficar escolhendo cor de pele e cabelo" apontam para a interface como um dos possíveis fatores que justificam o baixo uso de emojis com modificadores.

\section{Resultados qualitativos}

\section{Contexto Recife}

A primeira pergunta da entrevista abordou a dimensão pragmática, explorando a frequência de uso de emojis. A abordagem qualitativa permitiu observar outro potencial de objeto de estudo as figurinhas e os gifs, pela liberdade criativa de criar suas próprias imagens. Mas, em geral, todos utilizam emojis com frequência. Quanto à função do emoji, as respostas foram semelhantes entre usuários: para expressar emoções e reforçar mensagens.

A segunda pergunta, de natureza semântica, trata do que significa "representação" para os usuários. A premissa do Unicode Consortium, ao trabalhar com variações visuais de diferentes categorias de emoji, apoia-se em uma noção de representação política - etnia, gênero. Esses aspectos, contudo, não foram mencionados pelos usuários. Ao invés disso, os entrevistados relacionaram "representação" a um conceito mais amplo de identidade, que se relaciona com características físicas, comportamentos, gostos pessoais ou sentimentos específicos.

"Eu prefiro emoji com animais e desenhos. Os rostos humanos não me representam. Uso mais gatinhos." - usuário $S$

"Eu não me sinto representado por nenhum, mas gosto de usar a do grupo 5" [mulheres de cabelo liso e longo] - usuário F A

"Porque ele parece comigo fisicamente (cor da pele, estilo de corte de cabelo e barba)" - usuário J

Mesmo sem declarar o aspecto gênero para definir representatividade, a maioria dos usuários identificaram seus emojis de acordo com seus gêneros declarados, com exceção de 2 usuários que não se sentiram representados por nenhum emoji humano (de gênero neutro ou não). Durante a seleção, os usuários se concentravam nos emojis de seus gêneros correspondentes, para depois definir outras características (como tom de pele e corte/cor de cabelos). 
Por fim, os emojis considerados "representativos" não são usados no dia-dia pelos usuários, em função da falta de expressão e ações, coerente com as funções dos emojis anteriormente apontadas: expressar emoções e reforçar mensagens.

"Não tinha conhecimento desse emoji. Uso mais o rostinho (smiley). Porque eles expressam mais." usuário $\mathrm{C}$

"Eu só a utilizo quando refiro a mim mesma, e uso emoji mais pra falar para outros e para ações". usuário C B

Além disso, foi possível notar a influência das opções disponíveis na pesquisa na definição de emojis mais usados, pois nem todos os usuários estão familiarizados com o conjunto completo de emojis.

"Uso mais carequinhas (smileys). Falta de oportunidade. As pessoas também não usam, aí acabo não usando. As pessoas usam mais smileys, gifs e figurinhas, por isso uso-os também." - usuário A

Figura 19. Usuários entrevistados em Recife (elaborado pelos autores com consentimento dos entrevistados).

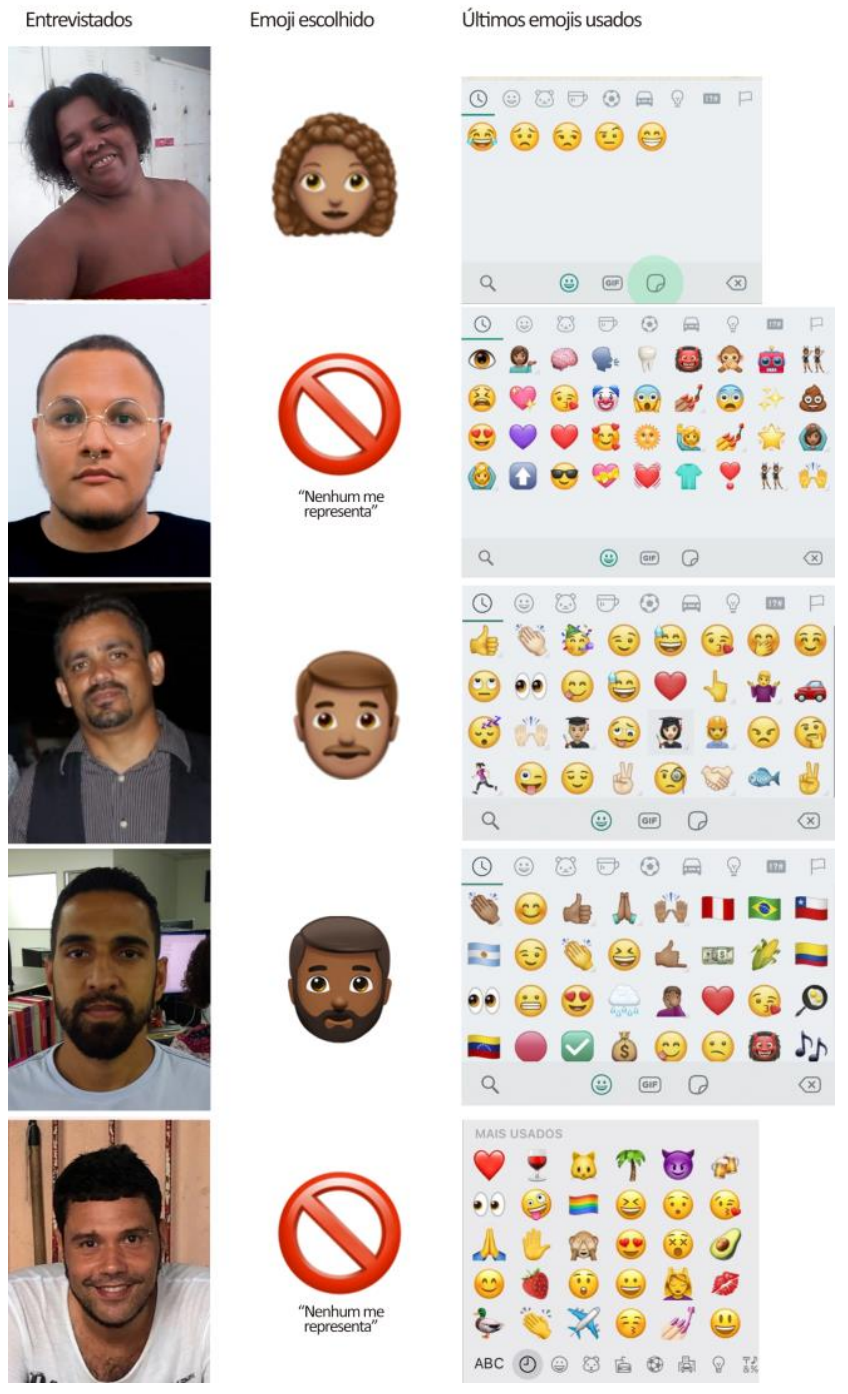

\section{Contexto São Paulo}

Semelhante a Recife, a abordagem qualitativa permitiu observar o potencial de figurinhas e gifs. O recurso está diretamente relacionado ao que os interlocutores costumam usar mais, estabelecendo uma linguagem comum. 
A função do emoji também varia de acordo com usuário. Para os usuários $C$ e $L$, ele é uma forma de tornar um texto mais atrativo:

"Minha relação com emoji é muito próxima, deixa a conversa mais atrativa. Torna tudo mais divertido e informal" - usuária C

"Por exemplo, uso emojis para fazer lista de compras. É mais fácil para recordar e é mais bonitinho." usuário L

Emojis também são usados para reduzir ambiguidades e facilitar as conversas. Apesar de sua natureza polissêmica, esses signos auxiliam a linguagem verbal quando usados em conjunto, como afirma o usuário R:

"[...] dizem que não me expresso muito bem. Uso para ironias, piadas, coisas relacionadas a nãoseriedade das mensagens." - usuário $\mathrm{R}$

Semelhante aos resultados de Recife, na segunda pergunta, de natureza semântica, os entrevistados relacionaram "representação" às características físicas, comportamentos, gostos pessoais e sentimentos.

"É como se fosse uma imagem espelhada do que sou: do que penso, do que sinto na situação." usuário $\mathrm{R}$

"Gosto de usar coisas que estão alinhadas com atividades que eu faço, que me representam. Por exemplo, eu corro e uso o emoji de corrida." - usuário L

"Personalidade. Algum emoji que tenha uma característica minha." - usuária G

A representação, inclusive, não se restringe à figura humana. Sob uma perspectiva sintático-semântica, formas que ilustram conceitos completamente diferentes podem se referir a um mesmo objeto:

"Também gosto de usar emojis que lembram a mim, como o 'esquilinho'." - usuária CM

A terceira pergunta restringiu o significado de "representação", associando imagens de emojis à percepção de representação dos usuários. Diante de um conjunto restrito de signos, usuários recorrem a noções limitadas de representação, como semelhança física. Cada usuário tem sua hierarquia de preferências, desde a negação de um aspecto (gênero, etnia) até priorização de corte de cabelo em relação ao tom de pele:

"Me reconheço como uma mulher branca de cabelo cacheado. Se tivesse a cartilha inteira, muito provavelmente não escolheria um bonequinho: é muito 'chumbadinho'. - usuária M

"Primeiro, pelo cabelo preso. Adoro cabelo preso. Depois, eu me vejo como mulher." - usuária CM

"Ainda me considero jovem, apesar de 'crescer fora do tempo'. Por dentro, me sinto jovem. E o amarelo... por não acreditar nessa coisa de branco, amarelo, gênero." - usuário $\mathrm{R}$

"Primeiro penso na etnia, porque sou preta. Quanto mais me identifico com isso, mais reafirmo isso.

Sempre que permite trocar de cor, eu troco." - usuária C

Como em Recife, todos os usuários identificaram seus emojis de acordo com seus gêneros declarados. Durante a seleção, os usuários se concentraram nos emojis de seus gêneros correspondentes, para depois definir outras características (como tom de pele e corte/cor de cabelos).

A quarta pergunta explorou o uso dos emojis selecionados como representativos. As respostas condizem com os resultados da pesquisa quantitativa, que destacou a proximidade entre emojis e emoções. Como os emojis "representativos" possuem uma expressão padrão, são pouco utilizados pelos usuários:

"Não diz nada, só é um bonequinho com cabelo ruivo." - usuária G

"Uso mais os de emoções, pois se aplicam mais no dia a dia." - usuária CM

Por fim, a última pergunta explorou como os emojis em questão poderiam ser mais representativos. Gênero, novamente, não surgiu explicitamente como aspecto prioritário. Em vez disso, eles abordam uma pluralidade de perfis e comportamentos:

"Embora tenha tons de pele, eles ainda são idênticos. Não tem mais nada que os distingue. Não tem corpinho tatuado, piercings... não tem emoji pra gordinha, com 'papadinha'..." - usuária M 
"Não tem o cabelo cacheado, como o black. Mas esses detalhes são importantes, porque me abriu opções, mesmo não usando." - usuária C

"Eles foram criados por um motivo: representar uma pessoa no momento, e não o gênero, classe, raça... a função do emoji é mais ser algo de sentimento e a maneira como você reagiu a determinado momento, não para mostrar quem eu sou." - usuário $R$

Figura 20. Usuários entrevistados em São Paulo (elaborado pelos autores com consentimento dos entrevistados).

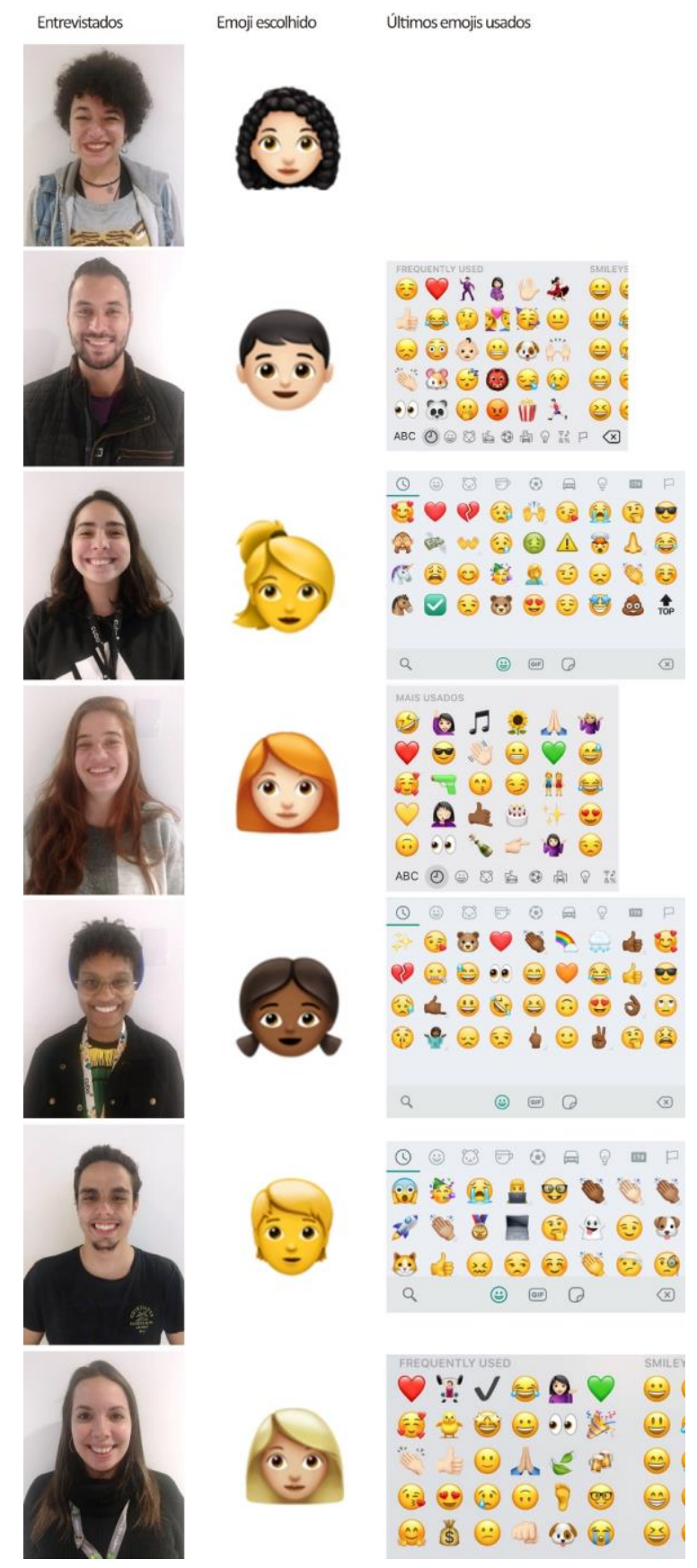

\section{Conclusão}

Gênero, apesar de pouco citado por usuários, é levado em consideração na escolha dos emojis que são mais representativos. A questão de representatividade surge em duas frentes:

Anais do 9 Congresso Internacional de Design da Informação | CIDI 2019 
usuários que utilizam emojis generificados, mas nem sempre declaram explicitamente suas opiniões; e usuários que utilizam somente os emojis do tipo "smiley", de emoções, por acreditar que são mais neutros.

O conceito de representatividade se mostra mais amplo que questões ideológicas. Pode-se traçar os critérios a partir dos pilares semântico (ao eleger uma característica de personalidade) ou sintático (semelhança física). Na maioria dos casos, representa valores mais abstratos - tais como emoções ("smileys" expressivos), conceitos ("panda", que é "fofo"), atividades ("corredor", que é "corrida") ou mesmo memórias afetivas ("girassol", que lembra "família").

A dimensão pragmática, contudo, demonstrou ser mais complexa do que previsto. A primeira descoberta aponta para a intenção de uso: emojis sintaticamente diferentes só se justificam quando representam valores diferentes. Em outras palavras: mais valem emojis com expressões diferentes que emojis com cabelos diferentes. A segunda descoberta revela desafios relacionados à interface de mensageiros instantâneos. A escolha de figuras humanas com suas variações de cor depende de mais interações com a interface quando comparada aos smileys, primeiros emojis disponíveis para seleção. Esforço de usuários, portanto, também se mostra como um critério relevante.

Tabela 2. Resumo das dimensões dos emojis e suas implicações para a base de usuários (elaborado pelos autores).

\begin{tabular}{|c|c|c|c|}
\hline $\begin{array}{l}\text { Comportamento } \\
\text { da base de } \\
\text { usuários }\end{array}$ & Recife & São Paulo & Em ambas cidades \\
\hline $\begin{array}{l}\text { Dimensão } \\
\text { pragmática }\end{array}$ & $\begin{array}{l}\text { Não apenas gênero } \\
\text { surge como um pré- } \\
\text { requisito de escolha, } \\
\text { mas também outras } \\
\text { características } \\
\text { identitárias. }\end{array}$ & $\begin{array}{l}\text { Gênero surge como um } \\
\text { pré-requisito de } \\
\text { escolha,"limitando" o leque } \\
\text { de opções no ato da } \\
\text { escolha. }\end{array}$ & $\begin{array}{l}\text { As principais intenções de } \\
\text { uso, pela perspectiva de } \\
\text { usuários, é representar } \\
\text { emoções, atividades, } \\
\text { gostos e características } \\
\text { associadas à } \\
\text { personalidade. } \\
\text { A interface cumpre papel } \\
\text { importante no uso de } \\
\text { emojis. Quanto mais } \\
\text { próximos e menos esforço } \\
\text { exigem de seus usuários, } \\
\text { mais provavelmente serão } \\
\text { utilizados. Smileys, dentre } \\
\text { os mais utilizados, são os } \\
\text { primeiros que surgem na } \\
\text { interface como opção de } \\
\text { escolha. }\end{array}$ \\
\hline $\begin{array}{l}\text { Dimensão } \\
\text { sintática }\end{array}$ & $\begin{array}{l}\text { Em se tratando de } \\
\text { figuras humanas, a cor } \\
\text { e a forma cumprem } \\
\text { papel importante para } \\
\text { seleção por } \\
\text { identificação (mesma } \\
\text { etnia, mesmo formato } \\
\text { de cabelo ou barba). }\end{array}$ & $\begin{array}{l}\text { Em se tratando de figuras } \\
\text { humanas, a cor cumpre } \\
\text { papel importante para } \\
\text { seleção, seja por } \\
\text { identificação (mesma } \\
\text { etnia) ou negação de } \\
\text { categorias (uso do } \\
\text { amarelo). }\end{array}$ & $\begin{array}{l}\text { A idade, delimitada pelo } \\
\text { uso de linhas e planos, } \\
\text { também é um aspecto } \\
\text { importante na escolha. } \\
\text { As formas que delimitam } \\
\text { diferenças entre homens e } \\
\text { mulheres, especificamente } \\
\text { em relação aos cabelos e } \\
\text { ao formato do rosto, } \\
\text { delimitam e funcionam } \\
\text { como critérios de escolha } \\
\text { para seleção de emojis. }\end{array}$ \\
\hline $\begin{array}{l}\text { Dimensão } \\
\text { semântica }\end{array}$ & & & $\begin{array}{l}\text { Figuras humanas não são } \\
\text { suficientes para } \\
\text { representar usuários, que } \\
\text { se entendem como um } \\
\text { conjunto de aspectos } \\
\text { relacionados a atividades, }\end{array}$ \\
\hline
\end{tabular}

Anais do 9 Congresso Internacional de Design da Informação | CIDI 2019 


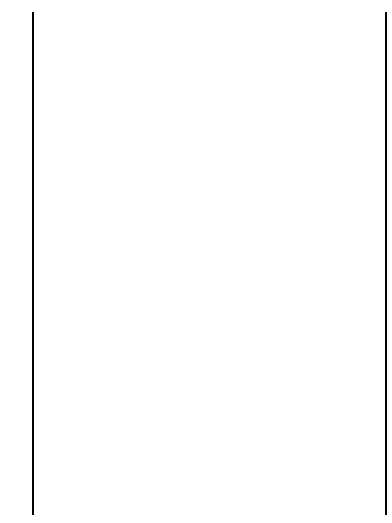

gostos, pensamentos e outras preferências.

Figuras humanas carecem de variação de expressões, reduzindo seu potencial significativo para usuários.

Qualquer emoji tem potencial de significar algo a usuários. Uma flor, um animal ou um objeto podem comunicar mais que figuras humanas.

Esse estudo exploratório abre outras possibilidades de pesquisa, mais complexas e abrangentes. Como se estabelecem as posições contrárias ou favoráveis à ampliação de representação em emojis? Como o público feminino, especificamente, interpreta a questão de gênero na comunicação digital? Que tipo de interface facilitaria o uso de emojis por parte dos usuários? Quais são os limites aceitáveis de representação por parte dos usuários? Estudos voltados a essas questões em muito podem contribuir para uma experiência de uso mais efetiva, com uma reflexão acerca da importância do design no contexto da comunicação e da cultura contemporânea.

\section{Referências}

Been, R. et al. (2016). Expanding Emoji Professions: Reducing Gender Inequality. The Unicode Consortium. Recuperado em fevereiro de 2019 de https://unicode.org/L2/L2016/16160emoji-professions.pdf.

Braida, F. \& Nojima, V. L. (2014). Tríades do design: Um olhar semiótico sobre a forma, o significado e a função. Rio de Janeiro: Rio Book's.

Butler, J. (2016). Problemas de gênero: feminismo e subversão da identidade. Rio de Janeiro: Civilização Brasileira.

Davis, M.; Edberg, P. (2017). Unicode Technical Standard \#51: Unicode Emoji. The Unicode Consortium. Recuperado em maio de 2017 de http://unicode.org/reports/tr51/.

EmojiXpress. (2019). EmojiStats. Recuperado em julho de 2019 de http://www.emojistats.org/.

Gomes Filho, J. (2006). Design do objeto: bases conceituais. São Paulo: Escrituras.

Gulşen, T. (2016). You Tell Me in Emojis. Computational and Cognitive Approaches to Narratology. Hershey, PA: IGI Global.

Klafke, R. F. (2019). Não é só um emoji: representações visuais de gênero em signos de mensageiros instantâneos entre 1996 e 2018. Dissertação (Mestrado). São Paulo, Brasil: Universidade de São Paulo.

Kress, G. \& van Leeuwen, T. (2006). Reading Images: the grammar of visual design. Londres: Routledge.

Leite, H. (2018). Observações do uso dos emojis: aspectos sintáticos, semânticos e pragmáticos na retórica visual de mensagens digitais. Dissertação (Mestrado). Recife, Brasil: Universidade Federal de Pernambuco.

Passos, R.; Mealha, O. \& Lima-Marques, M. (2015). Uma discussão sobre o objeto do design da informação. Anais do $7^{\circ}$ COngresso Internacional de Design da Informação. São Paulo: Blucher.

Rothenberg, M. (2013). Emojitracker. Recuperado em julho de 2019 de http://emojitracker.com/.

Unicode. (2019). Full Emoji List, v12.0. Recuperado em julho de 2019 de https://unicode.org/emoji/charts/full-emoji-list.html.

Anais do 9ำ Congresso Internacional de Design da Informação | CIDI 2019 


\section{Sobre o(a/s) autor(a/es)}

Raquel Klafke, Mestre, USP, Brasil <raquel.klafke@usp.br / raquel.klafke@gmail.com>

Hana Leite, Mestre, UFPE, Brasil <hanaluzia@gmail.com>

Daniela Hanns, PhD, USP, Brasil < dk.hanns@usp.br>

Hans Waechter, PhD, UFPE, Brasil <hnwaechter@terra.com.br> 